\title{
Proposta de alteração na forma como se ensina a Literatura Brasileira
}

\section{Maiquel Röhrig}

leuqiam@gmail.com

Instituto Federal do Rio Grande do Sul | Brasil

\section{Resumo}

0 presente artigo apresenta os fundamentos e resultados de uma atividade de extensão desenvolvida com professoras de Ensino Médio do município de São Borja-RS. 0 curso propunha uma forma alternativa de trabalhar a literatura em sala de aula. 0 objetivo era questionar a tradicional sistemática de trabalho da disciplina de literatura, pautada na historicização em detrimento da leitura dos textos propriamente ditos, e no estudo de autores e obras que se inicia nos períodos literários mais remotos em direção à contemporaneidade. A metodologia incluía aulas expositivas e dialogadas e a realização de seminários voltados à elaboração de planos de trabalho montados a partir da leitura dos contos.

\section{Palavras-chave}

Contos; história da literatura; literatura brasileira. 


\section{Introdução}

O modo como estudamos e como ensinamos literatura deriva de uma concepção teórica acerca dos fatos literários. 0 atual modelo de ensino da literatura concebe-a como produto de uma evolução histórica cuja compreensão ocorre mediante a leitura sistematizada em conformidade com uma linha de tempo que segue a cronologia, do período literário mais remoto ao contemporâneo. No entanto, nos livros didáticos que adotam este padrão, pouco se vê que seja efetivamente literário, e o que se lê são fragmentos escolhidos não para que se discutam questões estéticas e suas implicações éticas, políticas, filosóficas etc., mas, sim, para que se confirme o que se diz acerca daquele período no que concerne a suas características. Nesse sentido, enumeram-se autores, obras e suas respectivas características, numa perspectiva historicista que transforma as aulas de literatura em qualquer coisa muito diferente do que a discussão da literatura propriamente dita.

Isso ocorre a partir da eleição de um cânone literário entre os autores do passado. Então, relega-se, no último semestre do terceiro ano do Ensino Médio, a contemporaneidade ao estudo dos autores do terceiro tempo do modernismo, cujas obras, diga-se, foram escritas em meados do século XX. Opera-se, deste modo, o esquecimento dos textos atuais, sob a desculpa de que não se pode saber quais deles ficarão para a posteridade, incapazes que somos de eleger o cânone que nos representa. Essa lacuna, além de não contribuir com os objetivos da sistematização histórica, afasta os alunos da linguagem com a qual se identificam e impede-os de acessar os conteúdos que os afetam diretamente e que a literatura contemporânea apresenta.

\section{Contextualização}

Costumamos dizer que a literatura contemporânea não pode ser definida, porque não temos ainda o distanciamento temporal necessário para analisá-la de modo objetivo - e dizemos isso mesmo depois de, há muito tempo, a objetividade das análises em literatura ter sido questionada. Ou utilizamos a justificativa de haver hoje uma vasta produção que o tempo será capaz de filtrar, elegendo-se um cânone das obras representativas do período. Mas em um mundo pretensamente pós-moderno, sem metanarrativas, supostamente sem discursos hegemônicos, o estabelecimento de cânones parece anacrônico.

Esta dificuldade de estabelecer as leituras obrigatórias da literatura contemporânea, antes de ser justificada, deveria servir de justificativa para abandonarmos imposições de livros do passado para leitores que ainda não sabem reconhecer seu próprio tempo e linguagem. Poderia ser mais produtivo iniciar os trabalhos a partir da literatura contemporânea, para, 
Proposta de alteração na forma como se ensina a Literatura Brasileira

depois, explorar outras maneiras de interpretar o mundo, inclusive trabalhando textos de outros tempos de modo comparado. Da mesma forma, ao invés de criticarmos a preguiça e resistência dos leitores, acomodados com a literatura de massa, seria mais útil procurar entendê-la, e, a partir dela, apresentar a riqueza da literatura que consideramos superior, mas sem listas estanques, deixando nossa mente aberta para a diversidade. Pensando nisso, o curso de extensão intitulado "A trajetória do conto na literatura brasileira" trouxe para a discussão contos de autores desde contemporâneos até os românticos, num percurso histórico inverso ao que comumente se trabalha nas escolas.

Sabe-se que a leitura de textos literários em sala de aula estimula uma série de competências e desenvolve o gosto pela leitura. No entanto, é comum que os professores façam uso de textos literários nas séries iniciais do Ensino Fundamental e, depois, passem gradativamente a diminuir o trabalho com obras literárias, substituídas por artigos de opinião, editorias e, quando muito, crônicas que guardam resquícios de literariedade.

Os livros didáticos, por sua vez, utilizam os textos literários com finalidades linguísticas. Ao invés de trabalhar aspectos literários, como narração, ambientação, personagens, enredo etc., enfocam aspectos sintáticos, ortográficos, de pontuação, bem como questões rasas de interpretação textual, vistas, na maior parte dos casos, em relação a partes de textos, dificilmente considerando a integralidade de um conto ou poema.

A própria literatura é trabalhada em sala de aula de forma paradoxal: ao invés de se analisar os textos literariamente, propondo discussões e relações entre obras, opta-se pela historicização, enumerando obras e autores dentro de períodos literários. 0 mais próximo que se chega da literatura é a análise descontextualizada de figuras de linguagem, em geral pinçadas individualmente e descoladas da totalidade da obra.

Cada um desses procedimentos tem o seu valor, e não foi objetivo do curso de extensão "A trajetória do conto na literatura brasileira" intimidar os professores e coibir sua adoção. Ao contrário, o foco foi oferecer alternativas de trabalho com os textos literários propriamente ditos, uma vez que sua não utilização, ou seu uso para outros fins, deve ser contornado para que se consiga criar nos alunos o real gosto pela leitura, como fruição e fonte de cultura.

A subutilização dos textos literários em sala de aula ocorre por diversos motivos, entre os quais podemos aventar a perda da importância cultural da literatura em nossa sociedade, a dificuldade do trabalho com os textos literários causada pela diversidade de interpretações que eles provocam, bem como, talvez principalmente, a insegurança dos professores diante desse tipo de material. Afinal, como trabalhar com um objeto cuja análise pode ser tão plural quanto o número de seus leitores? Quais são as interpretações válidas e inválidas e como discernir entre o que se pode e o que não se pode dizer acerca do que foi lido? Quais devem ser os aspectos 
Proposta de alteração na forma como se ensina a Literatura Brasileira

trabalhados em cada obra? Que tipo de relações estabelecer com a realidade? Quais textos escolher em razão da faixa etária e conhecimentos prévios dos alunos?

Para responder a alguns desses questionamentos e diminuir a sensação de insegurança dos professores frente ao trabalho com a literatura, propus o referido curso de extensão no campus São Borja do Instituto Federal Farroupilha, voltado a professores da Educação Básica, independentemente do ano, para discutirmos obras e criarmos, juntos, planos de trabalho para serem aplicados nas turmas em que os professores participantes lecionavam.

0 curso foi ofertado à noite, das $19 \mathrm{~h}$ às $21 \mathrm{~h}$, nas dependências do próprio Instituto Federal Farroupilha. Contou com a participação de vinte professoras de escolas públicas estaduais e municipais, de nível Fundamental e Médio, as quais atuavam na cidade de São Borja. As aulas foram ministradas por mim, contando com a participação voluntária dos demais professores de Língua Portuguesa e Literatura do campus, que auxiliaram na seleção dos contos.

A opção pelo gênero conto se deu por diversos motivos. Em primeiro lugar, trabalhar com narrativas ficcionais atinge um grande número dos estudantes, dado que se trata de um gênero mais facilmente compreendido do que, por exemplo, os textos líricos, que contêm sintaxe mais elaborada e exigem uma iniciação à literatura que, em muitos casos, os alunos não têm. Além disso, um conto pode ser lido em sala de aula, diferentemente do romance, cuja leitura deve ser feita ou complementada em casa e, como sabemos, nesses casos a maioria dos estudantes não realiza a leitura das obras. Lido o conto em sala, ainda resta tempo, mesmo quando se trata de um único período de quarenta e cinco minutos, para conversar sobre o texto e iniciar atividades de interpretação, bem como organizar atividades posteriores.

A leitura em sala de aula garante que todos os estudantes tenham a experiência direta com as narrativas, e que possam discuti-las com os colegas e com o professor, expondo suas opiniões e interpretando o texto. A mediação do professor oferece a condição para os alunos aprofundarem sua compreensão da obra, tanto dos aspectos formais que a compõem quanto dos conteúdos nela representados.

Optei pelo trabalho a partir de textos contemporâneos, numa linha de tempo invertida até os românticos, para indicar aos professores que, assim, começávamos o trabalho pela linguagem com a qual os alunos se identificam para, gradativamente, os confrontarmos com o vocabulário e a sintaxe dos períodos anteriores.

\section{Justificativa do trabalho}

A literatura é uma ferramenta importante para a compreensão do mundo, na medida em que os textos operam com discursos que colocam diante do leitor diferentes perspectivas acerca do real através de estratégias de representação. Segundo Chartier (2002, p. 66), "não há prática 
Proposta de alteração na forma como se ensina a Literatura Brasileira

ou estrutura que não seja produzida pelas representações, contraditórias e afrontadas, pelas quais os indivíduos e os grupos dão sentido a seu mundo". Jozef (1986, p. 169) afirma que "A obra de arte é re-presentação da realidade, uma nova apresentação que a questiona. Toda linguagem é representação mas a da literatura é uma representação que se re-apresenta". Para a autora (JOZEF, p. 170), "Dentro da realidade estruturada, a criação literária cria seu próprio real, onde a irrealidade é condição obrigatória". Assim,

A literatura é sempre uma transformação da realidade. 0 ato poético autêntico engendra o real e esta recriação é condição básica para a existência de qualquer obra de arte. Consiste em nomear as coisas no reencontro poético com a palavra, que des-vela seu sentido já olvidado de tão automatizado. (JOZEF, p. 169)

Essa "transformação da realidade" se dá na linguagem. "Por meio dela, o escritor apreende a realidade em seu dinamismo e não como categoria fechada" (JOZEF, p. 185). Segundo Fiorin (2003, p. 54), "a linguagem condensa, cristaliza e reflete as práticas sociais, ou seja, é governada por formações ideológicas".

As professoras relataram, no início do curso, que optavam pelo trabalho com artigos de opinião e crônicas. Penso que explorar esses gêneros é importante, sobretudo na disciplina de Língua Portuguesa, mas nada substitui o contato com o texto literário, que, estranhamente, é deixado à parte inclusive na disciplina de Literatura.

Muitas crônicas possuem características literárias e exploram visões particulares de seus escritores. No entanto, trata-se, grosso modo, de um texto intencionalmente superficial para atender à demanda dos leitores de jornal, os quais não querem perder tempo com sofisticações na forma ou no conteúdo. A crônica tem que ser direta e conter uma linguagem simples, que possibilite uma compreensão instantânea.

Não é isso o que ocorre com a maioria dos textos literários, em seu sentido estrito. Eles, normalmente, exigem uma pausa reflexiva e disposição para enfrentar o refinamento da linguagem, através da qual buscam oferecer uma representação do real.

O real é uma construção discursiva, um conjunto de narrativas que interpretam eventos e os representam através de uma determinada linguagem. Ele é composto por diversas "camadas". Na camada mais profunda, o real é uma sequência de eventos que ocorrem num determinado recorte de tempo e num determinado espaço, cuja ocorrência prescinde de sua transformação em discurso para gerar efeitos. Entretanto, nós não temos acesso a essa camada profunda, apenas às camadas que se sobrepõem ao acontecimento. Nestas, há interpretações dos eventos que o representam através de uma determinada linguagem, e essas representações encontram na literatura um terreno muito fértil, o qual deve ser explorado pelos professores, a 
Proposta de alteração na forma como se ensina a Literatura Brasileira

fim de que os alunos saiam de seu lugar-comum, surpreendendo-se diante dos novos mundos que os textos oferecem.

Nem todos os estudantes têm condições de ler e compreender os textos sozinhos, e os professores devem mediar processos que desenvolvam a autonomia dos alunos. Por isso, foram trabalhadas diferentes formas de abordar os contos, a saber: por meio de leituras realizadas em grupo, mediadas pelo professor e, também, preparar os estudantes para leituras individuais. 0 trabalho do curso incidiu sobre estas estratégias de leitura e como desenvolver, a partir delas, discussões sobre as obras, as quais devem enfocar, principalmente, a análise do texto enquanto estrutura de sentidos.

\section{Metodologia do curso}

O curso foi organizado em doze aulas, cada uma de duas horas. O material de cada aula era enviado por e-mail para as participantes. No entanto, como estas afirmavam não ter tempo para ler os contos previamente, fazíamos a leitura em sala de aula. Antes, eu apresentava uma breve biografia de cada autor e comentava de que maneira sua obra inseria-se no período correspondente. Por meio de slides ou de livros, mostrava as capas de suas principais obras e comentava por alto os principais temas abordados e as formas recorrentes de sua produção literária.

O cronograma das aulas, os autores trabalhados e um breve resumo do que fizemos é apresentado a seguir:

Aula 1: Teoria do conto e autores do século XXI. Essa aula seguiu uma sistemática relativamente tradicional. Depois da apresentação individual dos participantes, expliquei como seria o curso e iniciei uma exposição acerca da teoria do conto. Fi-la utilizando-me de slides e conversei com as alunas sobre a principal ideia das teorias, o fato de todo conto contar duas histórias: uma que lemos na superfície, outra que interpretamos em suas camadas mais profundas. Lemos trechos da "Filosofia da composição", de Edgar Alan Poe e o conto "Maria de Lurdes não queria ser estuprada", de José Rezende Júnior, o qual discutimos para confirmar se a teoria fazia sentido.

Aula 2: Contemporaneidade do conto: Milton Hatoum, Dalton Trevisan e Luiz Vilela. Optei por estes autores por serem três figuras recorrentemente analisadas em dissertações de mestrado e teses de doutorado, além de terem recebido vários prêmios importantes nacionais e internacionais. A linguagem dos três é bastante acessível, uma 
Proposta de alteração na forma como se ensina a Literatura Brasileira

vez que os autores não recorrem a grandes experimentações linguísticas, o que facilita sua leitura, sobretudo em se tratando de adolescentes. Da mesma forma, as temáticas por eles exploradas versam sobre questões ao mesmo tempo atuais e perenes, revelando aspectos ao mesmo tempo contemporâneos e humanos, isto é, universais. Abordei, na aula, justamente essas características. Em relação a isso, pensamos coletivamente planos de aula para trabalhar com alunos do primeiro ano do Ensino Médio.

Aula 3: Cotidiano e violência nos contos de Lygia Fagundes Telles, Fernando Sabino e Rubem Fonseca. A temática da violência é pouco explorada na sala de aula. Ao lermos os contos, as professoras mostraram-se perturbadas e disseram que não poderiam levá-los para seus alunos. Pensaram que o conteúdo era muito pesado e a linguagem, muito direta, pesada. Depois de ouvi-las, fiz-lhes algumas perguntas no sentido de evidenciar que aquela linguagem era comum aos estudantes, e que o choque que ela nos causava era intencional e nada afetaria os adolescentes, isto é, não os "traumatizaria". Ao contrário, despertaria sua atenção. Uma delas, corajosamente, decidiu que levaria o conto "Feliz Ano Novo", de Rubem Fonseca, para sua turma. Na semana seguinte, ouvimo-la contar a experiência. Satisfeita, ela relatou que a aula foi um sucesso, e que os alunos, sem exceção, ficaram muito atentos ao conto.

Aula 4: Irreverência e profundidade nos contos de Apparício Silva Rillo. Escolhi este autor por ser um nome muito conhecido na cidade, posto ser um escritor local. Seus textos são cômicos, mas, ao mesmo tempo, revelam aspectos muito interessantes sobre a personalidade de seus personagens, os quais, por sua vez, em grande medida, relacionam-se conosco. Autores como Luis Fernando Verissimo e Stanilaw Ponte Preta podem ser utilizados nessa mesma perspectiva.

Aula 5: Imaginário e invenção linguística de Guimarães Rosa em "Sagarana" e "Primeiras estórias". Este autor possui uma densidade literária maior e exige que o professor verifique estratégias diferentes de trabalhá-lo. Sugeri que as professoras, ao invés de pedir que os alunos lessem os textos, fizessem isso por eles, em voz alta. 0 objetivo é fazer com que eles percebam o ritmo próprio dos textos de Guimarães Rosa e não se assustem com as dificuldades impostas por sua sintaxe. Pensamos em trabalhar várias dimensões dos contos, entre as quais a óbvia dimensão da linguagem e suas possibilidades na disciplina de Língua Portuguesa. Além desta, enfatizei os personagens e 
a riqueza interdisciplinar, com especial destaque à filosofia, no que tange às problematizações sobre a loucura e o amor realizadas pelos narradores.

Aula 6: Análise psicológica e simbolismo nos contos de Clarice Lispector. Destaquei da obra de Clarice os contos "Uma galinha" e "Amor". Nestes, pretendi que as professoras percebessem a temática feminista. Juntos, traçamos um plano de aula para trabalhar o assunto a partir dos símbolos das narrativas, com especial destaque para o "ovo", presente não apenas nestes contos, como também em grandes partes da obra da autora.

Aula 7: Precisão narrativa de Graciliano Ramos. 0 conto escolhido foi "Insônia", presente no volume homônimo. Em relação a este, trabalhamos aspectos formais como a repetição de palavras e o ritmo narrativo que procura reproduzir a monotonia e a angústia vividas pelo protagonista. Levei o capítulo "Baleia", do romance "Vidas secas", para trabalharmos juntos sobre a humanização da personagem, a cachorrinha que pensa e sonha como pessoa. Ao mesmo tempo, discutimos a animalização das personagens humanas, oprimidas pelo drama da seca.

Aula 8: Realismo mágico de Murilo Rubião e Mário de Andrade. As professoras ficaram fascinadas pelos contos "O edifício" e "O peru de Natal". Duas delas levaram as obras para trabalhar com seus alunos, e, apesar de algumas dificuldades, relataram que suas turmas haviam gostado da leitura. A principal dificuldade foi a preparação da leitura, uma vez que muitos adolescentes manifestaram desinteresse pela ideia de ler um texto que contivesse elementos tão fantasiosos. No entanto, após a leitura, a resistência foi vencida e a discussão, sobretudo de "O peru de Natal", segundo as professoras, foi muito proveitosa. Justificaram-no afirmando que a temática das relações familiares encontrou eco nos alunos, e muitos deles, ao se identificarem com o texto, participaram ativamente do debate promovido em classe.

Aula 9: Pré-modernismo de Lima Barreto e Monteiro Lobato. Trabalhamos o conto "O homem que sabia javanês" e "Negrinha". Em relação ao primeiro, discutimos o modo como muitos brasileiros vivem de "jeitinhos", encontrando formas escusas de sobreviver mediante o engodo dos outros. Sobre o segundo conto, traçamos planos de aula para pensar as formas de preconceito, sobretudo racial, presentes no Brasil. A ideia era fazer os alunos refletirem sobre como era e como é a discriminação, e de que modo ela está presente em nosso cotidiano, sob diferentes máscaras. 
Aula 10: Regionalismo e universalidade nos contos de João Simões Lopes Neto. Essa foi uma aula pensada em relação a um autor pré-modernista do Estado do Rio Grande do Sul. A ideia é que cada professor selecione um autor do seu próprio estado para analisar a linguagem e as temáticas deste autor, bem como o modo como elas, embora situadas em um espaço regional, apontam para dramas humanos universais.

Aula 11: Realismo e a superação do Realismo em Machado de Assis. O trabalho com nosso maior escritor pode ser realizado de inúmeras formas. Pensei em trabalhar pensando no período realista, elencando suas características e, ao mesmo tempo, problematizando o modo único como Machado de Assis cria seus textos, superando o realismo no mesmo instante em que o inaugura.

Aula 12: Contos românticos e precursores do gênero no Brasil. As professoras sentiram o mesmo embaraço que haviam expressado com os contos violentos de Rubem Fonseca ao serem apresentadas à "Noite na taverna", de Álvares de Azevedo. Pacientemente, tentei mostrar que a morbidez daqueles amores devassos, assassinos, ou, em uma palavra, satânicos, tinham imenso potencial para os adolescentes. Muito me alegrou receber, semanas mais tarde, um e-mail de uma das professoras relatando que o capítulo do livro intitulado "Johann" rendeu uma aula de muito sucesso, da qual os alunos participaram ativamente, experimentando um grande prazer com a narrativa dos amores incestuosos e criminosos de seus personagens.

Os objetivos do curso, além de trabalhar com os contos dos principais autores brasileiros e da literatura universal, incluíam ainda conhecer as características do gênero textual conto; entender o contexto histórico de cada conto abordado; ler os principais contos dos maiores autores da literatura brasileira e universal considerando as principais temáticas da literatura; organizar planos de aula com base em cada conto para trabalhá-los com os alunos da rede básica de ensino.

A justificativa que embasou a proposta respaldou-se no Plano de Desenvolvimento Institucional da instituição. A capacitação de professores relaciona-se aos objetivos dos Institutos Federais e é um elemento importante para aproximar a instituição de demais esferas públicas da educação, bem como estreitar as relações com a comunidade. Além disso, trabalhar com contos de modo eficiente, com o uso de um repertório diversificado e dos conhecimentos teóricos adequados, estimula o interesse pela leitura e aproxima alunos e professores. 
Proposta de alteração na forma como se ensina a Literatura Brasileira

Estabeleci, como resultados esperados com as atividades, que os participantes saíssem motivados para trabalhar com os contos junto com seus alunos, e que fossem capazes de fazê-lo de modo eficiente, estimulando seu interesse pela leitura e pelo aprendizado de modo geral. Também esperava que se convencessem de que a prática da leitura de obras literárias desenvolve as habilidades comunicativas fundamentais para o sucesso no mundo contemporâneo, bem como sensibiliza os estudantes para diversas formas de enxergar a realidade que nos cerca por meio da representação de personagens cujas experiências são conosco compartilhadas através do discurso literário.

Esses resultados foram, em grande medida, alcançados. As professoras participantes e a diretora de escola que acompanhou as atividades relataram ter levado os contos para suas escolas e compartilhado os planos de trabalho com suas colegas, as quais foram formalmente convidadas a participar da próxima edição do curso, a realizar-se no próximo ano, com novos contos e autores, a fim de, ao mesmo tempo, abarcar mais participantes e englobar as mesmas professoras que, tendo apreciado os trabalhos, solicitaram novas edições.

As aulas foram expositivas e dialogadas. Houve seminários de leitura e apresentação de fichas de leitura. Os contos eram enviados para o e-mail das participantes, a fim de que os trouxessem na aula, momento em que eram lidos e discutidos. Não foi solicitado que as professoras fizessem leitura prévia das obras, uma vez que não se queria correr o risco de que alguém não o fizesse por algum motivo e, por isso, não pudesse participar das análises e propostas de trabalho. Após a leitura, eram feitos planos de aula em conjunto para serem trabalhados com alunos da Educação Básica.

\section{Considerações finais}

A experiência direta com o texto literário deve ser estimulada na sala de aula. Depende do professor de Língua Portuguesa e Literatura proporcionar momentos em que esta não apenas ocorra, como também ocorra de modo significativo. No entanto, para isso é necessário que o professor esteja disposto a arriscar-se, pois discutir um texto literário, por mais que façamos um minucioso planejamento, estimula o imprevisível.

Mas, ao contrário de fugirmos à imprevisibilidade e nos protegermos na objetividade de aulas técnicas sobre aspectos gramaticais e históricos acerca dos textos, devemos dar espaço à exploração dos limites ficcionais da literatura. Deixar que os alunos dialoguem conosco e com os textos é fundamental para que aprendam com as possibilidades interpretativas e, também, com as interpretações erradas, as quais devem ser apontadas pelo professor. 
Proposta de alteração na forma como se ensina a Literatura Brasileira

Explicar por que uma interpretação é inválida é desafiante, mas, mais uma vez, o professor não deve se acovardar. Quando faltar coragem, sempre haverá um curso de extensão ou qualificação para fazer-nos recobrar o ânimo. Dentre os objetivos do curso, este foi um daqueles que foram alcançados. Espero que a semente que foi plantada gere frutos, e que as professoras contempladas pelo curso persistam no difícil trabalho de levar a literatura para dentro de suas salas de aula.

\section{Referências}

CHARTIER, ROGER. À beira da falésia: a história entre certezas e inquietude. Porto Alegre: Editora da UFRGS, 2002.

COSTA, Flávio Moreira da (org.). Os melhores contos brasileiros de todos os tempos. 3 ed. Rio de Janeiro: Ediouro Publicações, 2009.

DOHME, Vania. Técnicas para contar histórias. Rio de Janeiro: Vozes, 2010.

FIORIN, José Luiz. Interdiscursividade e intertextualidade. In: BRAIT, Beth (org.). Bakhtin: outros conceitos-chave. São Paulo: Contexto, 2006.

GOTLIB, Nádia Batella. Teoria do conto. 5 ed. São Paulo: Ática, 2010.

JOZEF, Bella. A mensagem e o enigma: a modernidade da representação à transgressão. Rio de Janeiro: Francisco Alves, 1986.

MORICONI, Ítalo (org.). Os cem melhores contos brasileiros do século. Rio de Janeiro: Objetiva, 2009.

BLOOM, Harold. O cânone ocidental: os livros e a escola do tempo. Tradução de Marcos Santarrita. Rio de Janeiro: Objetiva, 1995.

CANDIDO, Antonio. Formação da literatura brasileira: momentos decisivos. 8 ed. Belo Horizonte, Itatiaia, 1997.

CENSO DEMOGRÁFICO. Publicação crítica do recenseamento geral do império do Brasil de 1872. Disponível em http://www.nphed.cedeplar.ufmg.br/wpcontent/uploads/2013/02/Relatorio_preliminar_1872_site_nphed.pdf. Acesso em 16 dez. 2014.

CENSO DEMOGRÁFICO BRASILEIRO DE 2010. Disponível em http://www.ibge.gov.br/home/estatistica/populacao/censo2010/indicadores_sociais_municipa is/tabelas_pdf/tab28.pdf. Acesso em 16 dez. 2014.

COUTINHO, Eduardo. Comparativismo e historiografia literária. In: SEMINÁRIO INTERNACIONAL DA HISTÓRIA DA LITERATURA, 2, 1997, Porto Alegre. Anais. Porto Alegre: Edipucrs.

COUTINHO, Eduardo. Literatura comparada, literaturas nacionais e o questionamento do cânone. Revista Brasileira de Literatura Comparada, Rio de Janeiro, n. 3, p. 37-73, 1996. 
Proposta de alteração na forma como se ensina a Literatura Brasileira

JAUSS, Hans Robert. História da literatura como provocação à teoria literária. São Paulo: Ática, 1994.

LAJOLO, Marisa. Literatura e História da Literatura: senhoras muito intrigantes. In: MALLARD, Letícia et al (orgs.). História da literatura: ensaios. Campinas: UNICAMP, 1995. p. 19-36.

MIRANDA, Wander Melo. Nações literárias. Revista Brasileira de Literatura Comparada, São Paulo, n. 2, p. 31-38, 1994.

PERKINS, David. História da literatura e narração. Cadernos do Centro de Pesquisas Literária da PUCRS: série traduções, Porto Alegre, v. 3, n. 1, mar. 1999.

PERRONE-MOISÉS, Leyla. Altas literaturas. São Paulo: Companhia das Letras, 1998.

SCRAMIM, Susana. Cânone e liberdade. Revista Brasileira de Literatura Comparada, Belo Horizonte, n. 6, p. 239-250, 2002.

SCHMIDT, Siegfried J. Sobre a escrita da história da literatura: observações de um ponto de vista construtivista. In: OLINTO, Heidrun Krieger. Histórias da literatura: as novas teorias alemãs. São Paulo: Ática, 1996.

VEYNE, Paul. Como se escreve a história. Lisboa - Portugal: Edições 70, 1987. 
Proposta de alteração na forma como se ensina a Literatura Brasileira

\section{Proposal for change in the way it teaches Brazilian Literature}

\section{Abstract}

This paper presents the fundamentals and results of an outreach activity developed with high school teachers in São Borja-RS. The course proposed an alternative way of working literature in the classroom. The aim was to question the traditional system of work of literature discipline, based on the historicizing at the expense of reading the texts themselves, and the study of authors and works that begins in remote literary periods toward the present. The methodology includes expository and dialogue classes and seminars focused on the preparation of work plans assembled from reading the stories.

\section{Keywords}

Short stories; history of literature; Brazilian literature

Original submetido em: 11 abr. 2016

Aceito para publicação em: 25 jul. 2016

\section{Propuesta de cambio en la forma en que se enseña la literatura brasileña}

\section{Resumen}

Este artículo presenta los fundamentos y resultados de una actividad de extensión desarrollada con professoras de escuela secundaria en São Borja-RS. El curso ha propuesto una forma alternativa de trabajo de la literatura en el aula. El objetivo era cuestionar el sistema tradicional de trabajo de la disciplina literatura, basado en la historización a expensas de la lectura de los textos mismos, así como el estudio de autores y obras que se inicia en períodos literarios más lejanos hacia el presente. La metodología ha consistido en clases $y$ seminarios expositivos y dialogados se centraron en la preparación de planes de trabajo montadas a partir de la lectura de los cuentos.

\section{Palabras clave}

Novelas; historia de la literatura; literatura brasileña.

Sobre o autor:

\section{Maiquel Röhrig}

Doutor em Letras pela Universidade Federal do Rio Grande do Sul. Professor do Instituto Federal do Rio Grande do Sul - Campus Bento Gonçalves. 